\title{
Peptide-Guided Design of Mdm2/MdmX Inhibitors with Anticancer Activity
}

\author{
Lingyun Qin, Yao Chen, Rong Chen, Jinjin Zhou, Fei Yang, \\ and Zhengding Su*
}

Protein Engineering and Biopharmceutical Science Laboratory, the Key Laboratory of Fermentation of the Ministry of Education and Collaborative Innovation Center of Industrial Fermentation,

Hubei University of Technology, Wuhan, Hubei, China

\section{Introduction}

The $N$-terminal domains of MdmX or Mdm2 are highly homologous and have similar conformation (Figure $1 \mathrm{a} \& \mathrm{~b}$ ). There are three binding pockets for a p53 binding peptide (p53p), defined as F19, W23 and L26 on their surfaces. Current Mdm2 inhibitors including nutlin-3a exhibit weak binding affinity to MdmX. Nutlin-3a (Figure 1c) mimics p53p with high binding affinity to Mdm2 ( $K_{d} \sim 20$ $\mathrm{nM})$ but very weak to $\mathrm{MdmX}\left(K_{d} \sim 29 \mu \mathrm{M}\right)$. The L26 pocket significantly differentiates the binding affinities of nutlin-3a between Mdm2 and MdmX, but detailed mechanism remains unclear.

\section{Results and Discussion}

Drug Target Model: A short p53p peptide (p53p $\mathrm{p}^{\text {short }}$, Figure 2a) can occupy the F19 and W23 binding pockets on MdmX as well as Mdm2. A small molecule compound, HG201 (Figure 2b) adopted from current Mdm2/MdmX inhibitors, mimicking $\mathrm{p} 53 \mathrm{p}^{\text {short }}$ binding behavior, is used as a positive control.

High-Throughput Screening (HTS) of CTM Compound Library: The Cys76 residues on Mdm2 and MdmX are labeled with fluorescence probe, ANS, respectively.The protein-peptide complexes of MdmX-ANS/ p53 $\mathrm{p}^{\text {short }}$ and Mdm2-ANS/ p53 $\mathrm{p}^{\text {short }}$ are used as targets for HTS.

A natural compound library containing 2400 Chinese Traditional Medicinal Compounds (CTMs) are screened for leads. The compound concentration for screening was set at $20 \mu \mathrm{M}, 5 \mu \mathrm{M}, 1 \mu \mathrm{M}, 0.5 \mu \mathrm{M}$ and $0.3 \mu \mathrm{M}$, respectively.

Identification of Leads: The compound hits are ranked by FRET attenuation between the Trp23 of the p53p ${ }^{\text {short }}$ and the labelled-ANS on protein (Figure 3 Left). More than 15 hits were selected from screening at $20 \mu \mathrm{M}, 5 \mu \mathrm{M}, 1 \mu \mathrm{M}$ and $0.5 \mu \mathrm{M}$ of each compound (Figure 3 Middle). The three most potent leads selected at above $0.5 \mu \mathrm{M}$ and defined as HS201, HS202 and HS203 (Figure 3 Right), exhibited significant inhibition to the MdmX-p53 interaction.

Future Work: Resulting scaffold will be used to build a secondary model for searching target-specific functional group
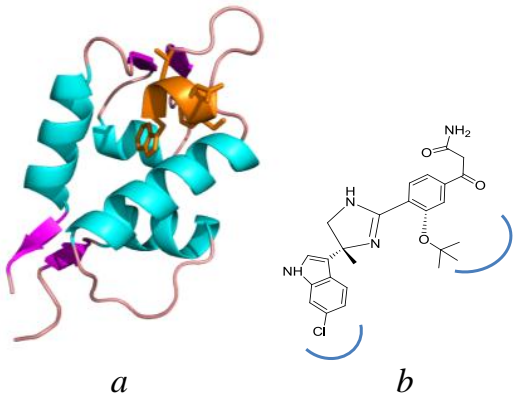

Fig. 2. (a). A protein target model is formed by a N-terminal domain in complex with a short p53p peptide. (b) A small molecule compound mimicking $p 53 p^{\text {short }}$ is used as a positive control. a)

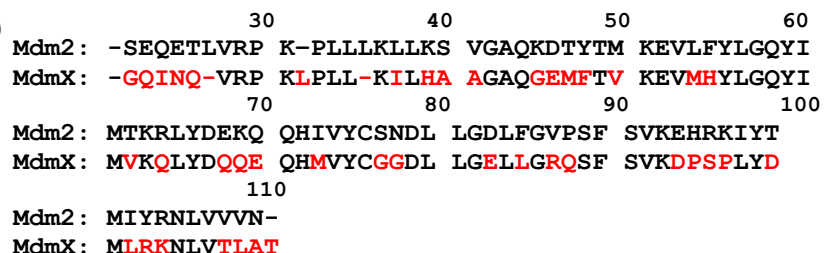

b)

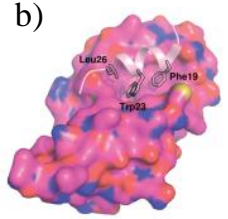

c)

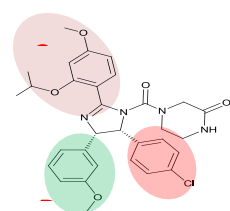

Fig. 1. (a) Alignment of N-terminal domains of Mdm2 and MdmX; (b) Three key residues, Phe18 (L19), Trp23(W23) and Leu29(L29), contribute to the high affinity of p53 peptide (p53p) binding to the domains; (c) A Mdm2 inhibitor, nutlin-3a, mimics p53p. 

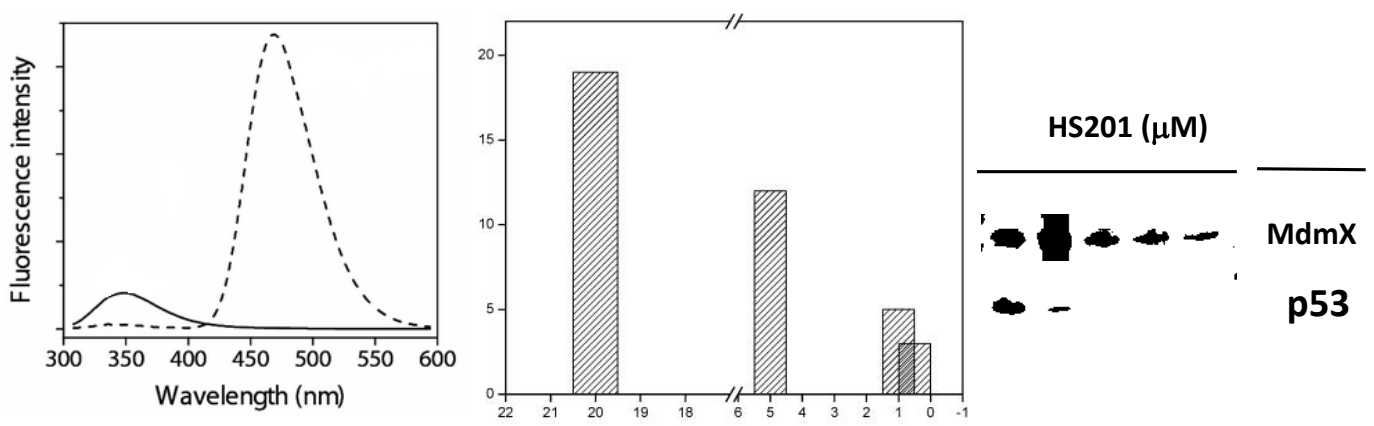

Fig. 3. Summary of HTS Hits. (Left) FRET happens between the Trp23 of p53p and the labelled-ANS on protein. (Middle) Numbers of hits decrease with decreasing threshold values; (Right) One of the three leads exhibits significant inhibition to the MdmX-p53 interaction, evaluated with western blot analysis using GST-MdmX pull-down experiment.

by screening virtual fragment library. Potent Mdm2-specific, MdmX-specific and dual specific inhibitors will be generated through fusing target-specific functional group to the scaffold. New inhibitors will be evaluated for their anticancer activities with cancer cell models.

\section{Acknowledgments}

This project was supported by Wuhan Science Research Grant (2015060101010033).

\section{References}

1. Wang, X., Jiang, X. FEBS Letters 586, 1390-1396 (2012), http://dx.doi.org/10.1016/i.febslet.2012.02.049

2. Wade, M., Li, Y.C., Wahl, G.M. Nature reviews Cancer 13, 83-96 (2013), http://dx.doi.org/10.1038/nrc3430

3. Hong, B., van den Heuvel, A.P., Prabhu, V.V., et al. Current Drug Targets 15, 80-89 (2014).

4. Muller, P.A., Vousden, K.H. Cancer Cell 25, 304-317 (2014), http://dx.doi.org/10.1016/j.ccr.2014.01.021

5. Wade, M., Wang, Y.V., Wahl, G.M. Trends in Cell Biology 20, 299-309 (2010),

http://dx.doi.org/10.1016/j.tcb.2010.01.009

6. Lane, D.P., Cheok, C.F., Lain, S. Cold Spring Harbor Perspectives in Biology, 2010, 2: a001222, http://dx.doi.org/10.1101/cshperspect.a001222

7. Popowicz, G.M., Domling, A.. Holak. T.A. Angewandte Chemie 50, 2680-2688 (2011), http://dx.doi.org/10.1002/anie.201003863

8. Vassilev, L.T., Vu, B.T., Graves, B., et al. Science 303, 844-848 (2004), http://dx.doi.org/10.1126/science.1092472

9. Su, Z.D., Royappa, G., Duda, D., et al. Symposium on Biomolecular Structure, Dynamics \& Function 1, 2 (2012).

10. Newman, D.J., Cragg, G.M. J. Natural Products 75, 311-335 (2012), http://dx.doi.org/10.1021/np200906s

11. Newman, D., Cragg. G. Bioorganic \& Medicinal Chemistry 17, $2105-2634$ (2009). 